\title{
Comparative analysis of DNA methylation changes in two contrasting wheat genotypes under water deficit
}

\author{
A. KAUR ${ }^{1,2}$, A. GREWAL ${ }^{2}$, and P. SHARMA ${ }^{1 *}$ \\ Division of Crop Improvement, Indian Institute of Wheat and Barley Research, ICAR, \\ Karnal, 132001, India ${ }^{1}$ \\ Division of Biotechnology, University Institute of Engineering and Technology, Kurukshetra University, \\ Kurukshetra, 136119, India ${ }^{2}$
}

\begin{abstract}
DNA methylation is one of the epigenetic mechanisms regulating gene expression in plants in response to environmental conditions. In this study, analysis of methylation patterns was carried out in order to assess the effect of water stress in two contrasting wheat genotypes using methylation-sensitive amplified polymorphism (MSAP). The results revealed that demethylation was higher in drought-tolerant genotype (C306) as compared to drought-sensitive genotype (HUW468) after experiencing drought stress. Comparisons of different MSAP patterns showed a high percentage of polymorphic bands between tolerant and susceptible wheat genotypes (from $74.79 \%$ at anthesis to $88.89 \%$ at tillering). Furthermore, differential DNA methylation in roots and leaves also revealed tissue-specific methylation of genomic DNA. Interestingly, 54 developmental stage-specific bands and 23 bands that were found contrasting between these two wheat genotypes were detected. Furthermore, a few sites with stable DNA methylation differences were identified between drought-tolerant and drought-sensitive cultivars, thus providing genotype-specific epigenetic markers. These results not only provide data on differences in DNA methylation changes but also contribute to dissection of molecular mechanisms of drought response and tolerance in wheat.
\end{abstract}

Additional key words: drought tolerance, methylation-sensitive amplified polymorphism, Triticum aestivum.

\section{Introduction}

Plants are constantly being challenged by biotic and abiotic stresses and thus have developed remarkable capabilities to modulate their physiological and developmental machinery through gene expression changes in response to these stresses (Zhou et al. 2007). Living organisms are different from non-living things due to their unique characteristics of growth, development, and reproduction. Instead of these features, they have a remarkable property that they can sense and respond to the environmental stimuli. Unlike animals, plants are sessile in nature. However, they can still act in response when encounter the perturbations of the environment. They have evolved certain mechanisms of action to adapt

to adverse conditions (Zhu 2002). In response to stresses, plants change their physiological and biochemical processes which, in turn, also affect their growth and productivity (Gupta and Huang 2014, Osakabe et al. 2014, Rejeb et al. 2014). Hence, how a plant will respond to a stimulus is well written in its genome. Still, there are some covalent modifications that do not belong to the genomic sequences but are nicely inherited with the genome. This phenomenon is known as "epigenetics". Epigenetics refers to the changes in genes expression other than alterations in DNA sequences (Boyko and Kovalchuk 2008). Many epigenetic activities like DNA methylation and histone modifications play an

Submitted 19 May 2017, last revision 28 October 2017, accepted 3 November 2017.

Abbreviations: AFLP - amplified fragment length polymorphism; DS - drought susceptible; DT - drought tolerant; MSAP - methylation-sensitive amplification polymorphism; NGS - next generation sequencing; PCR - polymerase chain reaction; RWC - relative water content.

Acknowledgments: The authors would like to thank the Director, the ICAR Indian Institute of Wheat and Barley Research, Karnal for providing necessary facilities for experiments. This work was supported by grants Nos. DWR/RP/10-3.5, 1007161, and 1008018 of the Indian Council of Agricultural Science, New Delhi and DBT-BBSRC (CGATE) of DBT to PS. Authors acknowledge the Maulana Azad National Fellowship by the University Grants Commission to AK. We thank laboratory members for their help during the experiments. This paper is IIWBR contribution No. 132.

* Corresponding author; e-mail: pradeep.sharma@icar.gov.in 
important role in the gene expression (Finnegan and Dennis 1993, Eichten et al. 2013). DNA methylation is an addition of a methyl group to cytosine bases of DNA to form 5'-methylcytosine. It is a conserved epigenetic mechanism in eukaryotes (Fang and Chao 2007, He et al. 2011) that changes the pattern of gene expression (Niederhuth and Schmit, 2014), genome plasticity and gene silencing (Choi and Sano 2007), and genomic immunity (Kim and Zilberman 2014). It also occurs in many bacterial and fungal species (Feng et al. 2010). Cytosine methylation controls gene expression by modulating proteins binding to DNA and structure of the associated chromatin (Osabe et al. 2014). Mostly, methylation in plants occurs in transposon-rich heterochromatic region, repeated sequences, and regions producing small interfering RNAs (Zhang et al. 2006). Methylation of promoter region can inactivate the expression of a gene while demethylation can lead to reactivation of gene and promoter-methylated gene expression in a tissue-specific manner (Zhang et al. 2006, Feng et al. 2010, Zemach et al. 2010).

Wheat (Triticum aestivum L.) is an allohexaploid and belongs to the family Poaceae (Gramineae), having $2 n=42(7 \times 3 \times 2)$ chromosomes, and genome size of $17 \mathrm{~Gb}$ (Willenborg and Van Acker 2008). Its huge genome size, polyploidy and high repeat content have made sequencing analysis challenging (Brenchley et al. 2012). However, recent advances in next generation sequencing (NGS) efforts have utilized targeted capture re-sequencing to analyze the genetic portion of hexaploid wheat (Winfield et al. 2012). Drought is one of the most severe abiotic stresses (Vinocur and Altman 2005) that reduces the yield of wheat by more than $50 \%$ (Amiri et al. 2013). Wheat cultivars differ greatly in their tolerance to drought. Genetically, drought tolerance is a complex trait under polygenic control and involves complex morpho-physiological mechanisms.

There are several methods to detect genome-wide

\section{Materials and methods}

Plants and growth conditions: Two genotypes of wheat (Triticum aestivum L.) used in this study were the drought-tolerant C306 and the drought-sensitive HUW468. The seeds procured from the ICAR-Indian Institute of Wheat and Barley Research, Karnal, India were surface sterilized in $0.1 \%(\mathrm{~m} / \mathrm{v}) \mathrm{NaClO}$ and rinsed several times before sowing in pots. Then, they were germinated in pots filled with a mixture of soil, sand, and Vermicompost in a ratio of $3: 1: 1$ (five seeds were sown in every pot) and cultivated under rain-out shelter. Four growth stages of wheat life cycle (i.e., tillering, booting, heading, and anthesis) were chosen to impose drought stress by withholding the water supply for $15 \mathrm{~d}$. Controls were regularly watered. After $15 \mathrm{~d}$ of drought stress at a particular stage, root and flag leaf samples were collected from controlled and stressed plants (Fig. 1 Suppl.). Their fresh mass was determined. Then, leaves were soaked in
DNA methylation patterns (Zilberman and Henikoff 2007, Gardiner et al. 2015). However, methylationsensitive amplified polymorphism (MSAP) has been considered as a suitable technique to evaluate DNA methylation polymorphism in wheat due to no requirement of prior genome information (Xu et al. 2000). First, it was reported by Xiong et al. (1999). It is based on amplified fragment length polymorphism (AFLP) technology (Vos et al.1995). Similarly to AFLP, it involves the digestion of genomic DNA with two methylation-insensitive isoschizomer enzymes $\mathrm{HpaII}$ and MspI. Both enzymes recognize the tetranucleotide sequence 5'-C/CGG-3', but have different sensitivities for methylation states. HpaII cannot cleave if one or both cytosines are fully methylated and cut only at hemimethylated external cytosine strands, whereas MspI cleaves only if internal cytosine is fully methylated (5'-C/ ${ }^{\mathrm{m}} \mathrm{CGG}-3$ ' but not 5'- ${ }^{\mathrm{m}} \mathrm{C} / \mathrm{CGG}-3$ ') but cannot cleave at external methylated cytosine (McClelland et al. 1994). In the past, MSAP analysis has been successfully performed in many plants including rice (Xiong et al. 1999, Sha et al. 2005), rape (Labra et al. 2004), oil palm (Jaligot et al. 2004), pepper (Portis et al. 2004), date palm (Fang and Chao 2007), cotton (Keyte et al. 2006), maize (Zhao et al. 2007, Lu et al. 2008, Tan 2010), cabbage (Salmon et al. 2008), grapevine (Schellenbaum et al. 2008), hops (Peredo et al. 2008), azalea (Meijon et al. 2009), sorghum (Zhang et al. 2011), horse gram (Bhardwaj et al. 2013), and barley (Chwialkowska et al. 2016). However, no such study has been reported in wheat under drought stress conditions.

In this study, two contrasting wheat genotypes, C306 (a drought-tolerant wheat genotype) and HUW468 (a drought-sensitive wheat genotype), were used to characterize DNA methylation changes in roots and leaves under drought stress at various developmental stages. The aim was to contribute to elucidation of the epigenetic mechanisms of wheat adaptation to drought stress. water in the dark for $4 \mathrm{~h}$ and their water saturated mass was measured. Further, dry mass of leaves was recorded after completely drying them in a hot air oven at $80{ }^{\circ} \mathrm{C}$. Then, the relative content (RWC) was calculated using the following formula (Smart and Bingham 1974): RWC $[\%]=[($ fresh mass - dry mass $) /$ water saturated mass - dry mass) $] \times 100$.

Methylation-sensitive amplified polymorphism: Genomic DNA was extracted from 100 - $200 \mathrm{mg}$ of both leaf and root tissues using a DNeasy Plant Mini Kit (Qiagen, Dusseldorf, Germany) according to the manufacturer's instructions. DNA was quantified on a NanoDrop spectrophotometer (NanoDrop Technologies, Delaware, USA) and confirmed by a $0.8 \%(\mathrm{~m} / \mathrm{v})$ agarose gel electrophoresis. Subsequently, two restriction digestions were performed with two isochizomeric enzymes (HpaII 
and MspI; 5'-C/CGG-3') along with EcoRI (5'-G/AATTC-3') in two separate reactions. In one reaction, $300 \mathrm{ng}$ of each DNA sample was double digested in CutSmart ${ }^{\circledR}$ buffer [New England Biolabs $(N E B)$, Ipswich, USA)] with two restriction enzymes, i.e., $20 \mathrm{U}$ EcoRI $(N E B)$ and $10 \mathrm{U} H p a I I(N E B)$ in a final reaction volume of $0.05 \mathrm{~cm}^{3}$ at $37{ }^{\circ} \mathrm{C}$ overnight. Similarly, another double digestion was carried out with $20 \mathrm{U}$ EcoRI $(N E B)$ and $20 \mathrm{U}$ MspI $(N E B)$ in CutSmart $^{\circledR}$ buffer $(N E B)$. The enzymes were inactivated by incubation at $65^{\circ} \mathrm{C}$ for $20 \mathrm{~min}$. A smear of digested products on $1 \%$ agarose gel electrophoresis indicated a complete digestion of DNA samples. EcoRI $(5 \mu \mathrm{M})$ and HpaII/MspI $(50 \mu \mathrm{M})$ adapters (Table 1 Suppl.) were ligated with the digested DNA samples with T4 DNA ligase (NEB) in $10 \times T 4$ DNA ligase buffer at $16^{\circ} \mathrm{C}$ for overnight. The ligation reactions were stopped by incubation at $65^{\circ} \mathrm{C}$ for $10 \mathrm{~min}$.

The digested-ligated products were diluted 10 times and preamplified in a $0.05 \mathrm{~cm}^{3}$ of PCR reaction volume containing $1 \times$ Taq buffer, $0.75 \mathrm{U}$ Taq polymerase (Bangalore Genei, Bangalore, India), $0.5 \mathrm{mM}$ dNTPs (Bangalore Genei), $0.2 \mu \mathrm{M} \mathrm{EcoRI} \mathrm{and} 0.2 \mu \mathrm{MMspI} /$ HpaII basic primers (Table 1 Suppl.). Pre-amplification was performed with the program having initial denaturation at $94^{\circ} \mathrm{C}$ for $5 \mathrm{~min}$, followed by 30 cycles of $94{ }^{\circ} \mathrm{C}$ for $1 \mathrm{~min}, 56{ }^{\circ} \mathrm{C}$ for $1 \mathrm{~min}, 72{ }^{\circ} \mathrm{C}$ for $2 \mathrm{~min}$, and a final extension at $72{ }^{\circ} \mathrm{C}$ for $10 \mathrm{~min}$. A $1.5 \%$ agarose gel electrophoresis was conducted using $0.005 \mathrm{~cm}^{3}$ of PCR products and a smear on the gel confirmed the preamplified products. The samples were diluted 10-fold to use further in the selective amplification reactions.

The selective amplification was carried out in a $0.02 \mathrm{~cm}^{3}$ of reaction mixture containing $0.5 \mu \mathrm{M} E c o$ RI and $0.5 \mu \mathrm{M}$ MspI/HpaII selective primers (Table 1 Suppl.), $1 \mathrm{mM}$ dNTPs, $1 \times$ Taq buffer, and $0.6 \mathrm{U}$ Taq polymerase. The touchdown PCR program was carried out with an initial denaturation at $94{ }^{\circ} \mathrm{C}$ for $3 \mathrm{~min}$ followed by a cycle at $94{ }^{\circ} \mathrm{C}$ for $30 \mathrm{~s}, 65^{\circ} \mathrm{C}$ for $30 \mathrm{~s}$, and $72{ }^{\circ} \mathrm{C}$ for $1 \mathrm{~min}$. In next 12 cycles, the annealing temperature was decreased by $0.7^{\circ} \mathrm{C}$ per cycle. Furthermore, the next 30 cycles were performed at $94{ }^{\circ} \mathrm{C}$ for $30 \mathrm{~s}, 56{ }^{\circ} \mathrm{C}$ for $30 \mathrm{~s}$ and $72{ }^{\circ} \mathrm{C}$ for $1 \mathrm{~min}$. Finally, the reaction was terminated after a final extension at $72{ }^{\circ} \mathrm{C}$ for $10 \mathrm{~min}$.

The PCR products of selective amplification were separated on $6 \%(\mathrm{~m} / \mathrm{v})$ denaturing polyacrylamide gel electrophoresis [acrylamide + bis-acrylamide (19:1), $7 \mathrm{M}$ urea, $10 \%(\mathrm{~m} / \mathrm{v})$ ammonium persulphate, $1 \%(\mathrm{v} / \mathrm{v})$ N,N,N',N'-tetramethylenediamine (TEMED)] in $1 \times$ Trisborate-EDTA (TBE) buffer. The gel was casted in SequiGen GT cell system (Bio-Rad, Hercules, USA) assembly and pre-run at $60 \mathrm{~W}$ for $30 \mathrm{~min}$. An equal amount of formamide gel loading dye $[95 \%(\mathrm{v} / \mathrm{v})$ formamide, $0.025 \%(\mathrm{~m} / \mathrm{v})$ Bromophenol blue, $0.025 \%(\mathrm{~m} / \mathrm{v})$ xylene cynol FF, and $5 \mathrm{mM}$ EDTA] was mixed with selective PCR samples and denatured at $95{ }^{\circ} \mathrm{C}$ for $5 \mathrm{~min}$. After denaturation, $0.008 \mathrm{~cm}^{3}$ of sample was loaded in each well and the gel was run at $60 \mathrm{~W}$ for about $2 \mathrm{~h}$. The gel was removed from the assembly and stained with silver staining method. Briefly, it was fixed in $7.5 \%$ acetic acid solution for $10 \mathrm{~min}$ and stained with $0.15 \%(\mathrm{~m} / \mathrm{v})$ silver nitrate solution containing $0.15 \%(\mathrm{v} / \mathrm{v})$ formaldehyde for $10 \mathrm{~min}$. The gel was rinsed briefly in deionised water. Further, the bands were developed using $30 \%(\mathrm{~m} / \mathrm{v})$ sodium carbonate solution containing $0.15 \%(\mathrm{v} / \mathrm{v})$ formaldehyde and $2 \mathrm{mg}$ of sodium thiosulfate for 3 to $5 \mathrm{~min}$. The reaction was stopped by keeping the gel in $7.5 \%(\mathrm{v} / \mathrm{v})$ acetic acid solution for $2 \mathrm{~min}$. The gel was dried overnight at room temperature and scanned.

The bands with strong intensity and high reproducibility were considered for analysis. The bands of MSAP were scored on the basis of their relative presence and absence in the gel using binary character matrix " 1 " and " 0 ", respectively. The criteria to find out polymorphism in the samples are listed in the Table 2 Suppl.

\section{Results}

This study was carried out to access the variation of DNA methylation pattern in drought-tolerant (DT) and droughtsensitive (DS) wheat genotypes at four growth stages (tillering, booting, heading, and anthesis). The plants were imposed to drought stress by withholding the water supply for $15 \mathrm{~d}$ (Fig. 1 Suppl.). A gradual reduction in RWC was observed in both genotypes after drought stress treatment at all stages (Fig. 1). A greater reduction of RWC was observed in DS genotype (HUW468) during booting and anthesis than in DT genotype (C306) (Fig. 1). It is concluded that tolerant wheat genotypes might respond to drought stress by minimizing loss of water and maintaining water uptake.

First of all, the differential pattern of DNA methylation was accessed in root samples of contrasting

wheat genotypes. For this reason, MSAP was followed using 45 combinations of EcoRI (E) and HpaII/MspI (HM) selective primers (Table 1 Suppl.). Out of 45 combinations, 8 primer pairs generated three types of clearly visible and reproducible bands and Type I bands were present in both EcoRI+HpaII and EcoRI+MspI lanes; type II bands in EcoRI+HpaII lanes, but not in $E c o \mathrm{RI}+M s p \mathrm{I}$ lanes, and type III bands in EcoRI $+M s p \mathrm{I}$ lanes, but absent in EcoRI+HpaII lanes. Variation in these three types of bands was used to access the polymorphism between the genotypes and within the genotypes under controlled and stressed conditions (Table 2 Suppl.). Polymorphic bands were further classified on the basis of occurrence of methylation and demethylation events (Zhong et al. 2009). 
A total of 535 scorable and reproducible amplified fragments were generated in roots by eight primer pairs (E1/HM2, E1/HM8, E2/HM8, E3/HM2, E3/HM3, E3/HM4, E3/HM6, and E4/HM3), out of which 135 (25.2\%), 154 (28.8\%), 127 (23.7\%), and $119(22.2 \%)$ bands were detected at tillering, booting, heading, and

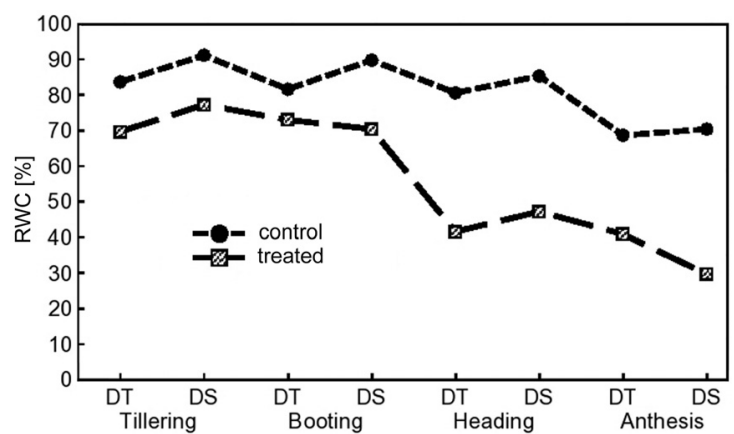

Fig. 1. The RWC in drought-tolerant (DT) and droughtsensitive (DS) wheat genotypes at tillering, booting, heading, and anthesis stages. Controls were sufficiently watered, but treated plants were not watered for $15 \mathrm{~d}$. anthesis stages, respectively. Thus, the result of MSAP analysis indicates the variable extent of genomic DNA methylation during the whole life cycle of wheat under drought stress conditions at different stages of growth. Furthermore, a DNA methylation polymorphism of $88.9 \%$ was detected at tillering followed by $84.4 \%$ at booting, $76.4 \%$ at heading, and $74.8 \%$ at anthesis stages between DT and DS genotypes (Fig. 2). It may indicate that plant refold itself more in early stages of growth to combat the stress and allow fewer changes toward the end of its life cycle during reproductive stages.

DNA methylation polymorphism pattern of DT and DS genotype was quite distinct at tillering (Table 1). The lowest number of bands was five and the highest was 53 for E3/HM2 and E1/HM8 primer combinations, respectively. A very high percentage of polymorphic bands was observed in DS genotype $(61.7 \%)$ in comparison to DT one (40.7\%) (Fig. 2 Suppl.). Out of them, nearly $31 \%$ lower methylation events occurred in DT genotype. Moreover, a higher percentage of hemimethylated events were detected in DS genotype $(24.75 \%)$ whereas DT genotype showed a higher number

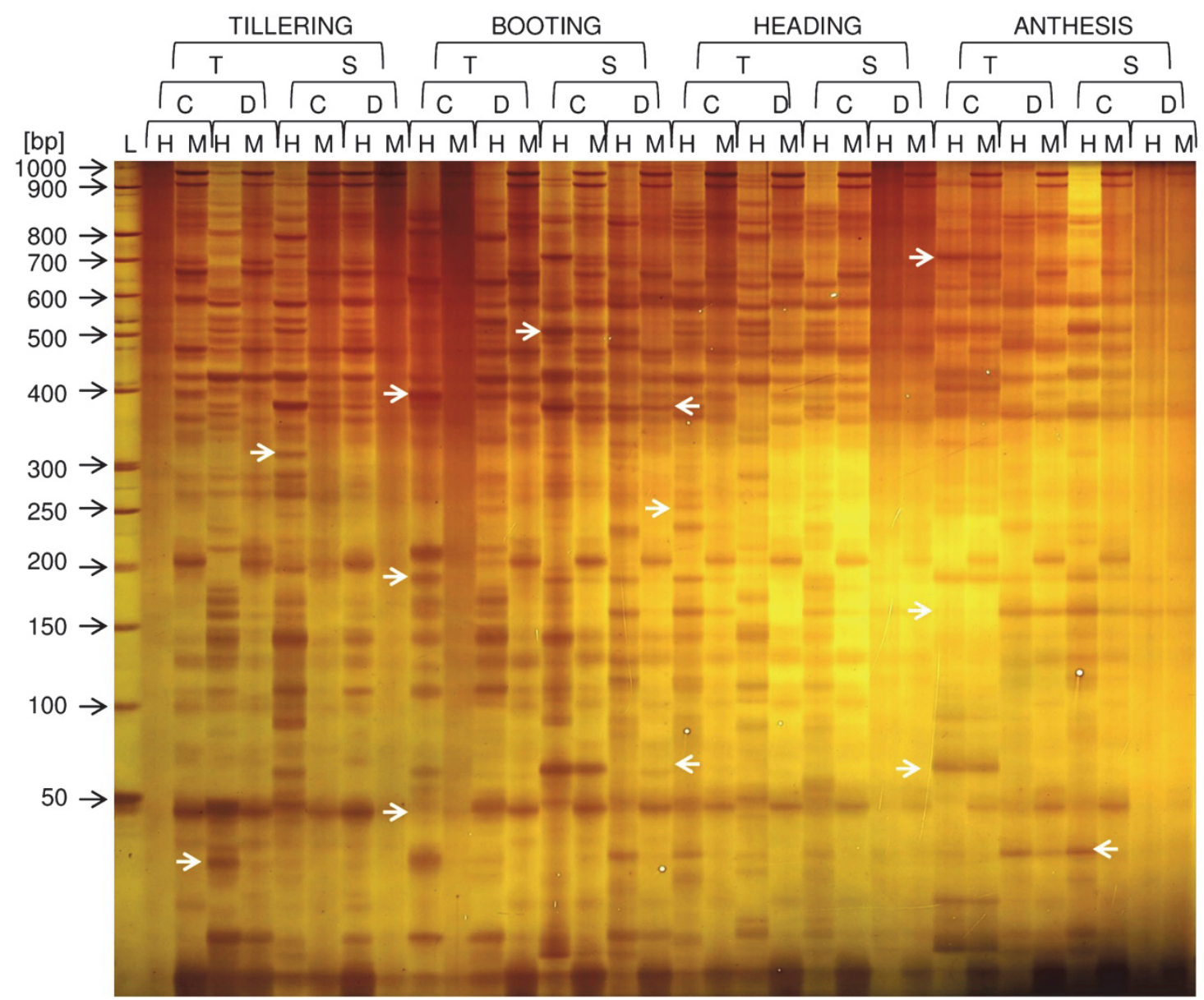

Fig. 2. Representative methylation pattern detected by $6 \%$ denaturing polyacrylamide gel electrophoresis using E1/HM8 primer pair in root samples at different growth stages of wheat. T - tolerant genotype, $\mathrm{S}$ - sensitive genotype, C - controlled condition, $\mathrm{D}$ - drought stress condition, $\mathrm{H}$ - samples digested with EcoRI/HpaII enzymes, M - EcoRI/MspI digested samples, and L - represents 50 bp ladder. 
of fully-methylated sites under both control (19.8\%) and stress conditions $(9.9 \%)$.

At booting stage, the minimum number of 5 bands and maximum 57 bands were detected in E1/HM2 and E1/HM8 primer combinations, respectively (Table 1). The number of polymorphic bands was 64 and 59 in DT and DS genotypes, respectively. Out of them, only $18.8 \%$ (29) methylation events occurred in DT genotype, but a higher percentage $(25.9 \%)$ of methylated bands were found in DS genotype (Fig. 2 Suppl.). However, an increase in fully-methylated sites was detected in DT wheat genotype $(17.3 \%)$ after stress treatment as compared to DS genotype where methylation decreased.

At heading stage, only four bands were observed in E1/HM2 primer combination whereas maximum 49 bands were detected in E1/HM8 primer pair (Table 2). A higher polymorphism was detected in DS genotype $(49.61 \%)$ in comparison to the DT $(39.4 \%)$ genotype (Fig. 2). The extent of methylation patterns was also very high in DS genotype (38.58\%) which was almost two times higher than that in DT genotype $(20.5 \%)$. The extent of hemi-methylated bands increased in DT genotype $(17.3 \%)$ as compared to DS genotype (4.95\%) after stress treatment. A similar trend was observed for fully-methylated sites at this stage.

At anthesis, the maximum 36 bands were noticed in E1/HM8 whereas only 3 bands were observed in both E1/HM2 and E4/HM3 primer combination (Table 2.). Similar to the tillering, booting, and heading stages, the number of methylated events also remained higher in DS genotype in contrast to the DT genotype at anthesis stage (Suppl. Fig. 3). Notably, DS genotype without stress showed more fully-methylated and hemi-methylated sites while it was vice-versa in DS genotype after drought stress.

In order to detect the stage-specific patterns, the bands which were only detected at a particular stage were counted. As a result, a total of 54 bands (10.1\%) were

Table 1. Methylation polymorphism (number of detected loci) in drought-tolerant (DT) and drought-sensitive (DS) wheat genotypes during drought stress at tillering and booting stages ( $\mathrm{mm}$ - monomorphic, pm - polymorphic, meth - methylation events, dem demethylation events)

\begin{tabular}{|c|c|c|c|c|c|c|c|c|c|c|c|c|c|c|}
\hline Primers & $\begin{array}{l}\text { Tillering } \\
\text { total }\end{array}$ & $\begin{array}{l}\mathrm{mm} \\
\mathrm{DT}\end{array}$ & DS & $\begin{array}{l}\text { pm } \\
\text { meth } \\
\text { DT }\end{array}$ & DS & $\begin{array}{l}\text { dem } \\
\text { DT }\end{array}$ & DS & $\begin{array}{l}\text { Booting } \\
\text { total }\end{array}$ & $\begin{array}{l}\mathrm{mm} \\
\mathrm{DT}\end{array}$ & DS & $\begin{array}{l}\text { pm } \\
\text { meth } \\
\text { DT }\end{array}$ & DS & $\begin{array}{l}\text { dem } \\
\text { DT }\end{array}$ & DS \\
\hline E3/HM2 & 5 & 5 & 4 & 0 & 1 & 0 & 0 & 12 & 7 & 9 & 5 & 2 & 0 & 1 \\
\hline E1/HM2 & 10 & 7 & 6 & 2 & 2 & 1 & 2 & 5 & 3 & 4 & 0 & 1 & 2 & 0 \\
\hline E3/HM3 & 11 & 10 & 3 & 1 & 7 & 0 & 1 & 10 & 7 & 8 & 1 & 0 & 2 & 2 \\
\hline E3/HM6 & 19 & 11 & 6 & 5 & 8 & 3 & 5 & 25 & 11 & 17 & 8 & 6 & 6 & 2 \\
\hline E1/HM8 & 53 & 19 & 19 & 4 & 25 & 30 & 9 & 57 & 32 & 30 & 4 & 18 & 21 & 9 \\
\hline E4/HM3 & 9 & 5 & 7 & 0 & 2 & 4 & 0 & 10 & 5 & 6 & 5 & 4 & 0 & 0 \\
\hline E2/HM8 & 19 & 15 & 6 & 1 & 3 & 3 & 10 & 25 & 17 & 17 & 4 & 3 & 4 & 5 \\
\hline E3/HM4 & 9 & 8 & 1 & 0 & 7 & 1 & 1 & 10 & 8 & 4 & 2 & 6 & 0 & 0 \\
\hline Total & 135 & 80 & 52 & 13 & 55 & 42 & 28 & 154 & 90 & 95 & 29 & 40 & 35 & 19 \\
\hline$[\%]$ & & 59.3 & 38.5 & 9.6 & 40.7 & 31.1 & 20.7 & & 58.4 & 61.7 & 18.8 & 25.9 & 22.7 & 12.3 \\
\hline
\end{tabular}

Table 2. Methylation polymorphism (number of detected loci) in drought-tolerant (DT) and drought-sensitive (DS) wheat genotypes during drought stress at heading and anthesis stages (mm - monomorphic, pm - polymorphic, meth - methylation events, dem demethylation events)

\begin{tabular}{|c|c|c|c|c|c|c|c|c|c|c|c|c|c|c|}
\hline Primers & $\begin{array}{l}\text { Heading } \\
\text { total }\end{array}$ & $\begin{array}{l}\mathrm{g} \\
\mathrm{DT}\end{array}$ & DS & $\begin{array}{l}\text { pm } \\
\text { meth } \\
\text { DT }\end{array}$ & DS & $\begin{array}{l}\text { dem } \\
\text { DT }\end{array}$ & DS & $\begin{array}{l}\text { Anthesi } \\
\text { total }\end{array}$ & $\mathrm{s}$ & DS & $\begin{array}{l}\text { pm } \\
\text { meth } \\
\text { DT }\end{array}$ & DS & $\begin{array}{l}\text { dem } \\
\text { DT }\end{array}$ & DS \\
\hline E3/HM2 & 9 & 5 & 7 & 2 & 0 & 2 & 2 & 18 & 8 & 16 & 8 & 0 & 2 & 2 \\
\hline E1/HM2 & 4 & 1 & 2 & 1 & 2 & 2 & 0 & 3 & 0 & 2 & 2 & 1 & 1 & 0 \\
\hline E3/HM3 & 8 & 6 & 7 & 2 & 0 & 0 & 1 & 9 & 5 & 8 & 4 & 0 & 0 & 1 \\
\hline E3/HM6 & 14 & 7 & 10 & 3 & 4 & 4 & 0 & 17 & 9 & 12 & 3 & 3 & 5 & 2 \\
\hline E1/HM8 & 49 & 28 & 14 & 8 & 33 & 13 & 2 & 36 & 18 & 12 & 10 & 23 & 8 & 1 \\
\hline E4/HM3 & 5 & 4 & 3 & 1 & 2 & 0 & 0 & 3 & 2 & 1 & 0 & 2 & 1 & 0 \\
\hline E2/HM8 & 29 & 20 & 16 & 7 & 6 & 2 & 7 & 24 & 15 & 15 & 2 & 3 & 7 & 6 \\
\hline E3/HM4 & 9 & 6 & 5 & 2 & 2 & 1 & 2 & 9 & 5 & 4 & 1 & 5 & 3 & 0 \\
\hline Total & 127 & 77 & 64 & 26 & 49 & 24 & 14 & 119 & 62 & 70 & 30 & 37 & 27 & 12 \\
\hline [\%] & & 60.6 & 50.4 & 20.5 & 38.6 & 18.9 & 11.0 & & 52.1 & 58.8 & 25.2 & 31.1 & 22.7 & 10.1 \\
\hline
\end{tabular}


found to be unique to a particular stage. Out of them, $17(12.6 \%), 18(11.7 \%)$, and $15(12.6 \%)$ stage-specific bands were detected at tillering, booting, and anthesis stages, respectively. However, only 4 bands (3.2\%) were spotted as heading stage-specific. Similarly, we also detected the bands which showed the contrasting pattern in DS and DT genotypes under control and stressed conditions. The highest number of contrasting bands was found at heading stage between DT and DS wheat genotypes, i.e. 9 bands $(7.1 \%)$ (data not shown). Furthermore, $7(5.2 \%), 3(1.9 \%)$, and $4(3.4 \%)$ contrasting bands between DT and DS were observed at tillering, booting, and anthesis stages.

To compare the status of methylation in roots with leaves, the MSAP analysis was further carried out in leaf samples using three primers which produced reproducible bands in root samples (Fig. 3 Suppl.). Interestingly, the pattern of DNA methylation in leaves was quite similar to banding pattern of roots. However, demethylation events occurred more in DT genotype while more methylation events were identified in DS genotype. On the other hand, a lower level of DNA methylation polymorphism was observed in leaf tissue as compared to root tissue. The pattern of hemi-methylated and fully-methylated sites in roots and leaves remained the same for both the genotypes. Only 3 stage-specific differential banding patterns were identified in leaf samples, which were 9fold lower than in roots (27 bands). Similarly, just onethird of the total contrasting bands ( 8 bands) were spotted in leaves as compared to roots (17 bands). Therefore, methylation might play a big role in biochemical and morphological changes that occur in roots to make a plant tolerant to drought.

\section{Discussion}

Wheat productivity is heavily affected by biotic and abiotic stresses. Hence, it is the need to understand its responses to the environmental cues. Wheat has a very large and complex genome (Mayer et al. 2014). Therefore, MSAP could be considered a robust method to find out the pattern and extent of genome-wide methylation. In this study, wheat really displayed a high DNA methylation polymorphism at different growth stages (Figs. 2 and 3 Suppl.). A higher level of DNA methylation polymorphism was observed at vegetative growth stages (tillering and booting) as compared to the reproductive stages (heading and anthesis) (Figs. 2 and 3 Suppl.). It might indicate that plants allow fewer alterations in gene expression at reproductive stages. The differential level of polymorphism in DNA methylation at different stages of growth also revealed the developmental stage-specific modulations of DNA methylation. However, these changes ranged from $74.8 \%$ at anthesis to $88.9 \%$ at tillering stage which might be due to their presence in transposable elements that comprises $>80 \%$ of the wheat genome. The DNA methylation measured at different developmental stages in rice, sorghum, or Arabidopsis (Ruiz-Garcia et al. 2005, Xiong et al. 1999, Zhang et al. 2011) is only $16-40 \%$. Generally, the methylation increases as the tissue matures (Messeguer et al. 1991, Ruiz-Garcia et al. 2005). A similar observation was noticed in the present study showing an increase in methylation trends from tillering to anthesis stage in DT wheat genotype while it did not follow the same pattern (Fig. 2) in DS genotype.

Methylation, generally, occurs in transposable elements and repeated sequences. The polymorphism

observed in wheat plants is also quite high. Some of the highly methylated regions in Arabidopsis are transcriptionally inactive heterochromatic regions including centromeres and pericentromeres. The DT genotype of wheat showed a higher number of demethylation events in comparison to DS genotype at all stages (Fig. 2 Suppl.). It could be a strong clue of the close association of drought tolerance with a higher gene expression in the DT genotype than in DS genotype. These will open new avenues for a better understanding of the plant stress adaptation mechanisms.

In the present study, we found that the degree of DNA methylation polymorphism was relatively higher in roots than in leaves. It revealed a tissue-specific or organspecific cytosine methylation in wheat under drought stress conditions. Similarly, in several other studies, the level of DNA methylation has also been found different among different organs or between different developmental stages. For instance, the DNA methylation is higher in tomato seeds than in mature leaves (Gallusci et al. 2016). In rice, a higher DNA methylation has been detected in seedlings than in flag leaves (Xiong et al. 1999).

In this study, the higher demethylation was observed in the drought-tolerant wheat genotype than in the drought-sensitive genotype. However, the DS genotype showed a genome-wide hyper-methylation after drought stress treatment while overall hypo-methylation was observed in DT genotypes. Thus, these significant variations in DNA methylation pattern would definitely help in understanding the mechanisms of drought tolerance in wheat.

\section{References}

Amiri, R., Bahraminejad, S., Jalali-Honarmand, S.: Effect of terminal drought stress on grain yield, and some

morphological traits in 80 bread wheat genotypes. - Int. J. Agr. Crop Sci. 5: 1145-1153, 2013. 
Bhardwaj, J., Mahajan, M., Yadav, S.K.: Comparative analysis of DNA methylation polymorphism in drought sensitive (HPKC2) and tolerant (HPK4) genotypes of horse gram (Macrotyloma uniflorum). - Biochem. Genet. 51: 493, 2013.

Boyko, A., Kovalchuk, I.: Epigenetic control of plant stress response. - Environ. mol. Mutagenesis 49: 61-72, 2008.

Brenchley, R., Spannagl, M., Pfeifer, M., Barker, G.L.A., D' Amore, R., Allen A. M.: Analysis of the bread wheat genome using whole-genome shotgun sequencing. - Nature 491: 705-710, 2012.

Choi, C.S., Sano, H.: Abiotic-stress induces demethylation transcriptional activation of a gene encoding a glycerophosphodiesterase-like protein in tobacco plants. - Mol. gen. Genom. 277: 589-600, 2007.

Chwialkowska, K., Nowakowska, U., Mroziewicz, A., Szarejko, I., Kwasniewski, M.: Water-deficiency conditions differently modulate the methylome of roots and leaves in barley (Hordeum vulgare L.). - J. exp. Bot. 67: 1109-1121, 2016.

Eichten, S.R., Briskine, R., Song, J., Li, Q., Swanson-Wagner, R., Hermanson, P.J., Waters, A.J., Starr, E., West, P.T., Tiffin, P., Myers, C.L., Vaughn, M.W., Springera, N.M.: Epigenetic and genetic influences on DNA methylation variation in maize populations. - Plant Cell 25: 2783-2797, 2013.

Fang, J.G., Chao., C.T.: Methylation-sensitive amplification polymorphism in date palms (Phoenix dactylifera L.) and their off-shoots. - Plant Biol. 9: 526-533, 2007.

Feng, S., Cokus, S. J ., Zhang, X ., Chen, P.Y., Bostick, M., Goll, M. G., Hetzel, J., Jain, J., Strauss, S.H ., Halpern, M.E., Ukomadu, C., Sadler, K.C., Pradhan, S., Pellegrini, M., Jacobsen, S.E.: Conservation and divergence of methylation patterning in plants and animals. - Proc. nat. Acad Sci. USA 107: 8689-8694, 2010.

Finnegan, E.J., Dennis, E.S.: Identification by sequence homology of a putative cytosine methyltransferase from Arabidopsis thaliana. - Nucl. Acids Res. 21: 2383-2388, 1993.

Gallusci, P., Hodgman, C., Teyssier, E., Seymour, G.B.: DNA methylation and chromatin regulation during fleshy fruit development and ripening. - Front. Plant Sci. 7: 807, 2016.

Gardiner, L.J., Tulloch, M.Q., Olohan, L., Price, J., Hall, N., Hall, A.: A genome-wide survey of DNA methylation in hexaploid wheat. - Genome Biol. 16: 273-288, 2015.

Gupta, B., Huang, B.: Mechanism of salinity tolerance in plants: physiological, biochemical, and molecular characterization. - Int. J. Genom. 2014: 1-18, 2014

He, X.J., Chen, T., Zhu, J.K.: Regulation and function of DNA methylation in plants and animals. - Cell. Res. 21: 442-465, 2011.

Jaligot, E., Beule, T., Baurens, F.C., Billotte, N., Rival, A.: Search for methylation-sensitive amplification polymorphisms associated with the "mantled" variant phenotype in oil palm (Elaeis guineensis Jacq.). - Genome 47: 224-228, 2004

Keyte, A.L., Percifield, R., Liu, B., Wendel, J.F.: Infraspecific DNA methylation polymorphism in cotton (Gossypium hirsutum L). - J. Heredity 97: 444-450, 2006.

Kim, M.Y., Zilberman, D.: DNA methylation as a system of plant genomic immunity. - Trends Plant Sci. 19: 320-326, 2014.

Labra, M., Grassi, F., Imazio, S., Fabio, T.D., Citterio, S., Sgorbati, S., Agradi, E.: Genetic DNA-methylation changes induced by potassium dichromate in Brassica napus L. Chemosphere 54: 1049-1058, 2004.
Lu, Y., Rong, T., Cao, M.: Analysis of DNA methylation in different maize tissues. - J. Genet. Genomics 35: 41-48, 2008.

Mayer, K.F.X., Rogers, J., Doleel, J., Pozniak, C., Eversole, K., Feuillet, C., Gill, B., Friebe, B., Lukaszewski, A.J., Sourdille, P., et al.: A chromosome-based draft sequence of the hexaploid bread wheat (Triticum aestivum) genome. Science 345: 1251788, 2014.

McClelland, M., Nelson, M., Raschke, E.: Effect of site-specific modification on restriction endonucleases and DNA modification methyltransferases. - Nucl. Acids Res. 22: 3640-3659, 1994.

Meijon, M., Valledor, L., Santamaria, E., Testillano, P.S., Risueno, M.C., Rodriguez, R., Feito, I., Canal, M.J.: Epigenetic characterization of the vegetative floral stages of azalea buds: dynamics of DNA methylation and histone $\mathrm{H} 4$ acetylation. - J. Plant Physiol. 166: 1624-1636, 2009.

Messeguer, R., Ganal, M.W., Steffens, J.C., Tanksley, S.D.: Characterization of the level target sites and inheritance of cytosine methylation in tomato nuclear DNA. - Plant mol. Biol. 16: 753-770, 1991

Niederhuth, C.E., Schmitz, R.J.: Covering your bases: inheritance of DNA methylation in plant genomes. - Mol. Plants 7: 472-480, 2014.

Osabe, L., Clement, J.D., Bedon, F., Pettolino, F A., Ziolkowski, L., Llewellyn, D.J., Finnegan, E.J., Wilson, I.W.: Genetic DNA methylation changes in cotton (Gossypium) genotypes tissues. - PLoS ONE 9: e86049, 2014.

Osakabe, Y., Osakabe, K., Shinozaki, K., Tran, L.S.: Response of plants to water stress. - Front. Plant Sci. 5: 1-8, 2014.

Peredo, E.L., Arroyo-Garcia, R., Reed, B.M., Angeles-Revilla, M.: Genetic and epigenetic stability of cryopreserved and cold-stored hops (Humulus lupulus L). - Cryobiology 57: 234-241, 2008.

Portis, E., Acquadro, A., Comino, C., Lanteri, S.: Analysis of DNA methylation during germination of pepper (Capsicum annuит L) seeds using methylation-sensitive amplification polymorphism (MSAP). - Plant Sci. 166: 169-178, 2004.

Rejeb, I.B., Pastor, V., Mauch-Mani, B.: Plant responses to simultaneous biotic and abiotic stress: molecular mechanisms. - Plants 3: 458-475, 2014.

Ruiz-Garcia, L., Cervera, M.T., Martinez-Zapater, J.M.: DNA methylation increases throughout Arabidopsis development. - Planta 222: 301-306, 2005.

Salmon, A., Clotault, J., Jenczewski, E., Chable, V., Manzanares-Dauleux., M.J.: Brassica oleracea displays a high level of DNA methylation polymorphism. - Plant Sci. 174: 61-70, 2008.

Schellenbaum, P., Mohler, V., Wenzel, G., Walter, B.: Variation in DNA methylation patterns of grapevine somaclones (Vitis vinifera L). - BMC. Plant Biol. 8: 78, 2008.

Sha, A.H., Lin, X.H., Huang, J.B., Zhang, D.P.: Analysis of DNA methylation related to rice adult plant resistance to bacterial blight based on methylation-sensitive AFLP (MSAP) analysis. - Mol. gen. Genom. 273: 484-490, 2005.

Smart, R.E., Bingham, G.E.: Rapid estimates of relative water content. - Plant Physiol. 53: 258-260, 1974.

Tan, M.: Analysis of DNA methylation of maize in response to osmotic and salt stress based on methylation-sensitive amplified polymorphism. - Plant Physiol. Biochem. 48: 2126, 2010

Vinocur, B., Altman, A.: Recent advances in engineering plant tolerance to abiotic stress: achievements and limitations. - 
Curr. Opin. Biotechnol. 16: 123-132, 2005.

Vos, P., Hogers, R., Bleeker, M ., Reijans, M., Van de Lee, T., Hornes, M., Frijters, A., Pot, J., Peleman, J., Kuiper, M., Zabeau, M: AFLP: a new technique for DNA fingerprinting. - Nucl. Acids Res. 23: 4407-4414, 1995.

Willenborg, C.J., Van Acker, R.C.: The biology and ecology of hexaploid wheat (Triticum aestivum L) and its implications for trait confinement. - Can. J. Plant Sci. 88: 997-1013, 2008.

Winfield, M.O., Wilkinson, P.A., Allen, A.M., Barker, G., Coghill, J.A., Burridge, A.: Targeted re-sequencing of the allohexaploid wheat exome. - Plant Biotechnol. J. 10: 733742, 2012.

Xiong, L.Z., Xu, C.G., Saghai-Maroof, M.A., Zhang, Q.: Patterns of cytosine methylation in an elite rice hybrid and its parental lines, detected by a methylation-sensitive amplification polymorphism technique. - Mol. gen. Genom. 261: 439-446, 1999.

Xu, M., Li., X., Korban., S.S.: AFLP-based detection of DNA methylation. - Plant mol. Biol. Rep. 18: 361-368, 2000.

Zemach, A., McDaniel., I.E ., Silva., P., Zilberman, D.: Genome-wide evolutionary analysis of eukaryotic DNA methylation. - Science 328: 916-919, 2010.

Zhang, L., Xu, C., Von Wettstein, D., Liu, B.: Tissue-specific differences in cytosine methylation their association with differential gene expression in Sorghum bicolor. - Plant Physiol. 156: 1955-1966, 2011.

Zhang, X., Yazaki, J., Sundaresan, A., Cokus, S., Chan., S.W.L., Chen., H., Henderson, I.R., Shinn, P., Pellegrini, M., Jacobsen, S.E., Ecker, J.R.: Genome-wide highresolution mapping functional analysis of DNA methylation in Arabidopsis. - Cell 126: 1189-1201, 2006.

Zhao, X., Chai, Y., Liu, B.: Epigenetic inheritance and variation of DNA methylation level and pattern in maize intraspecific hybrids. - Plant Sci. 172: 930-938, 2007.

Zhong, L., Xu, Y., Wang, J.: DNA-methylation changes induced by salt stress in wheat Triticum aestivum. - Afr. J. Biotechnol. 8: 6201-6207, 2009.

Zhou, J., Wang, X., Jiao, Y., Qin, Y., Liu, X., He, K., Chen, C., Ma, L., Wang, J., Xiong, X., Zhang, Q., Fan, L., Deng X.W.: Global genome expression analysis of rice in response to drought and high-salinity in shoot, flag leaf, and panicle. - Plant mol. Biol. 63: 591-608, 2007.

Zhu, J. K.: Salt and drought stress signal transduction in plants. - Annu. Rev. Plant Biol. 53: 247-273, 2002

Zilberman, D., Henikoff, S.: Genome-wide analysis of DNA methylation patterns. - Gene Develop. 134: 3959-3965, 2007. 